\title{
High-density housing in Palestine: learning from traditional typologies
}

\author{
M. Itma \\ School of Architecture, University of Minho, Portugal
}

\begin{abstract}
The need for high-density housing is increasing in Palestine. The dramatic limitation of land and the high demand for housing is greatly influencing urban qualities. Besides which, the current types of settlements contain a lot of disadvantages. These are mostly low-rise, low-density, or high-rise, high-density types of housing, which usually consist of independent typologies. In addition, the traditional typologies are mainly delivered from the courtyard prototype. They form a compact fabric that can contain a high-density of the population. However, the influence of traditional typologies is rarely found in the contemporary housing of Palestine. This paper investigates the values of the traditional typologies in order to propose them as a possible choice for future development. The investigation leads to the following conclusions: the traditional typologies have the advantages of both low-rise and high-rise independent typologies. They also characterize the whole settlement with great values based on socio-cultural sustainability, which are rarely found in contemporary housing: minimal waste of outdoor spaces, ability to growth, adaptability, environmental adequacy, and minimal infrastructure and services.
\end{abstract}

Keywords: settlement type, traditional housing, compact fabric, high-density, Palestine.

\section{Introduction}

Housing typologies are an important issue to be considered when creating designs for specific conditions. Through history, humans had to have a lot of housing typologies, such as single houses, attached houses, courtyard houses, and others. These typologies were nationally invented and developed through time by societies to meet their lifestyle, and also to adapt to the surrounding environment (Rapoport [1]). 
Housing typologies are not free standing units that can be designed without affecting the surrounding. Settlements are considered as an organism, using inadequate units will affect the whole settlement qualities (Caniggia and Maffei [10]). Therefore there is a strong relation between the part and the whole, thinking of what parts are being used is highly important.

This issue was highlighted in Europe beginning in the second half of the twentieth century. Team 10 started to find new concepts of form and function on top of the concepts of early Modernism. This period showed the revival of "Mat buildings" (Zhu [18]). These are attached, low-rise and high-density building types (Sarkis et al. [5]). The Free University of Berlin (1963-1974) by Candilis, Josic and Woods is a good example of mat buildings. It was based on an unfinished-flexible system of design. A modular unit was used to give the architecture the ability to grow around courtyards. Growth was in a natural way according to future needs (Sarkis et al. [5]). Other contemporary experiences of housing projects based on this concept are also taking places around the world (fig. 1). Using courtyards enhances this idea and leads to many environmental and social values (Schittich [3]).

However, the courtyard house is rarely used in the contemporary housing in Palestine, though it was the main prototype of urban housing until the beginning of the twentieth century (Al-Amad [11]). In fact, it is possible to learn from the traditional houses to improve the current qualities (Al-Amad [15]). Most of Palestinian traditional houses still highly populated, and probably they can satisfy current socio-cultural needs.
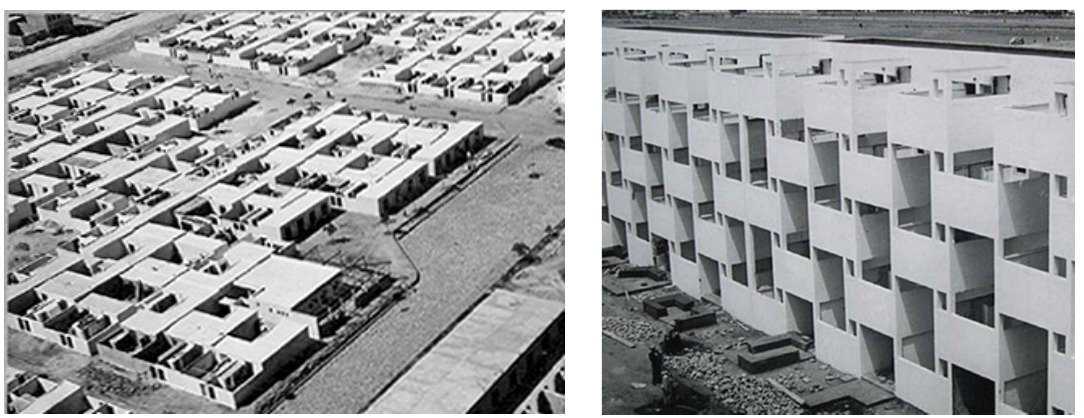

Figure 1: ATBAT - Afrique housing: horizontal and vertical courtyard housing in Morocco, By Candilis and Wood 1953 (Sarkis et al. [5]).

\section{Contemporary housing in Palestine}

The twentieth century showed a sudden transformation in the urban fabric in Palestine. A dispersed type of settlement was used instead of compact fabric. It was the starting of adapting detached houses, instead of courtyard houses, which were built outside the walls of traditional cities. Independent typologies started to grow randomly and fast, which affected the whole urban forms. In the second half 
of the century, rising vertically became common to provide high-density, and continued to be used widely in the Palestinian cities.

A peace agreement in Oslo was signed in 1993, to give the Palestinians a temporary authority on separated parts of their land. As a result, the Palestinian Authority controls approximately $40 \%$ of the land called: zone A, and B (fig. 2) (The World Bank [19]). Consequently land lots become very limited and expensive (Abu hantash and Salah [16]). Because of this relatively peace period, a wide range of housing projects are taken place in most of the Palestinian cities (zone A), causing an up normal density in the residential areas.

To increase the efficiency of these projects, the used typologies should be evaluated, judged and improved. An alternative possibility for the future can be also highlighted. The following text will analyze briefly the contemporary housing in Nablus city, which is one of the most important cities in Palestine (Doumani [9]). Selected samples are in the contemporary nonprofit housing, these projects were built after Oslo agreement. Two common types of settlements were chosen: low-rise, low-density (1-2 floors) and high-rise, high-density (more than 4 floors).

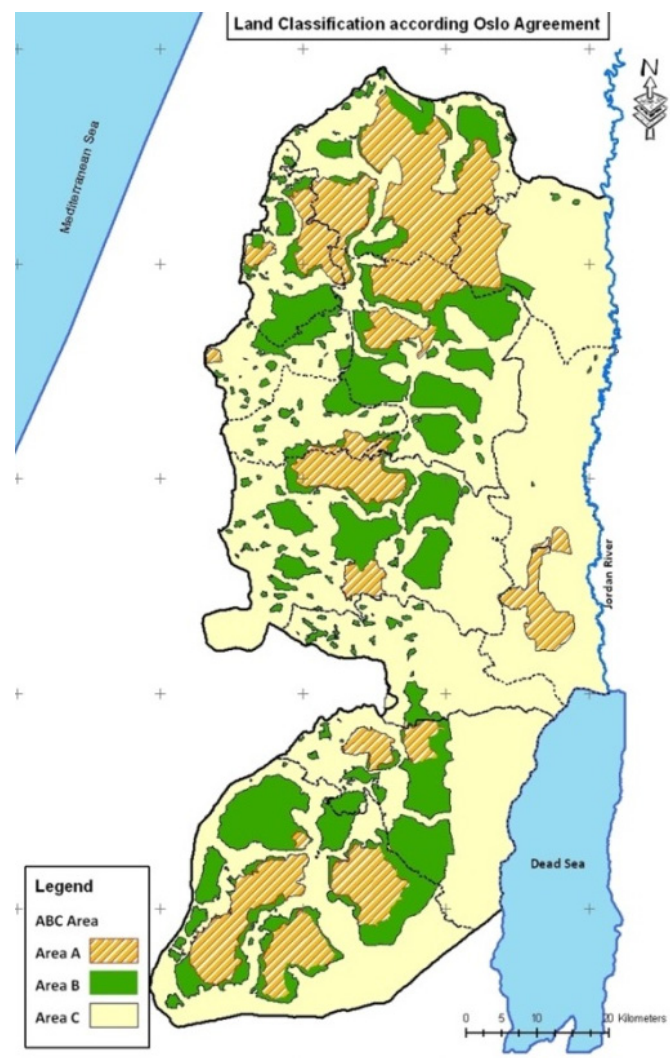

Figure 2: The limitation of land in the West Bank, Palestine (P. H. G. [20]). 


\subsection{Low-rise low-density housing}

Low-rise low-density housing in Nablus city is usually consists of detached and semi-detached typologies, one to two floors in height (fig. 3). It is mostly found in the suburbs of the city. The local families prefer to accommodate this housing due to their cultural habits, basically to find privacy.

This type of settlements has many disadvantages, mainly the failure of containing high-density of population. This fact is increasing costs of dwellings, infrastructure, and daily mobility of habitants to their work (Schittich [3]). Besides, these typologies are not an inefficient tool of using land, for example large parts of private gardens are just for show and not a multifunctional use.
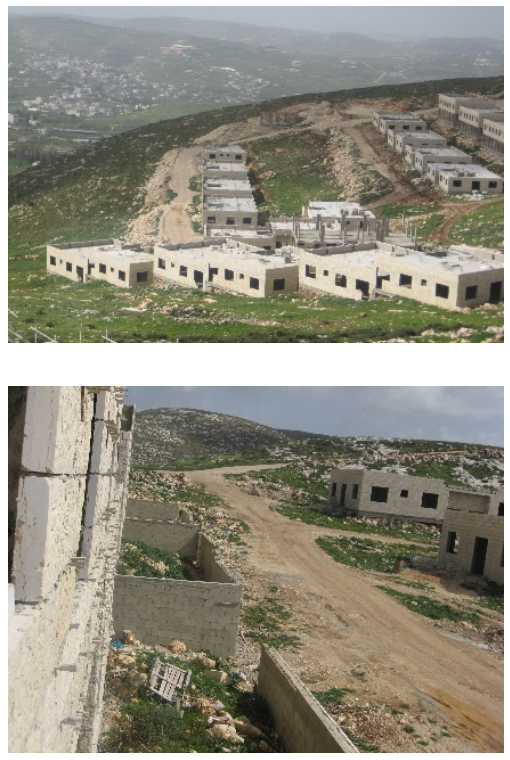

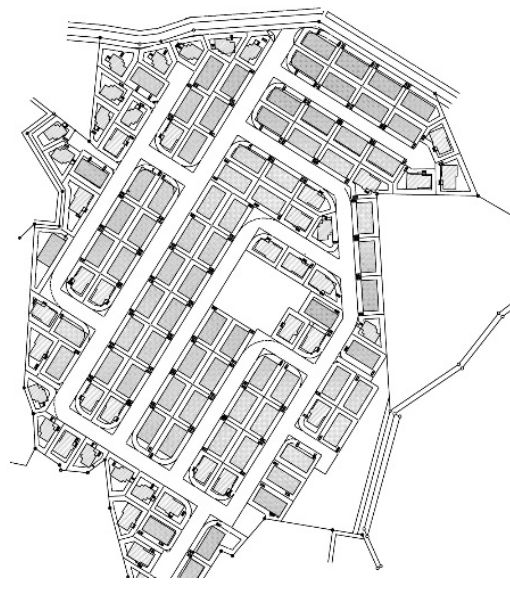

Figure 3: Low-rise low-density housing, Nablus city.

\subsection{High-rise high-density housing}

High-rise high-density housing in Nablus city is usually a composition of a number of independent apartment buildings, it is widely found inside the city. Each building consists of a central staircase with 2-4 apartments around it. High prices of land lots prompt the designers to raise the building vertically in the same land - more than four floors. They attempt to solve the problem of affordability by creating other equivalent ones (Wolbier [6]).

Public spaces for social interaction and children playing are rarely considered in this type of settlements. Most of the outdoor spaces are not exceeding the left space between buildings, with much consideration for cars than humans (fig. 4). Inadequate arrangement failed in some parts to provide air and sun for the surroundings (Abu Obaid [14]), causing lack of compliance with the conditions of 
health. The lack of adequate outdoor spaces also causes social problems (Schittich [3]). It has a bad reflection on normal social relationships and causes distractions in behavior (Barker [7]). This is pushing families to prefer single houses with a private gardens, which is not a sustainable typology of urban housing, especially within the limitation of lands (Pfeifer and Brauneck [2]).
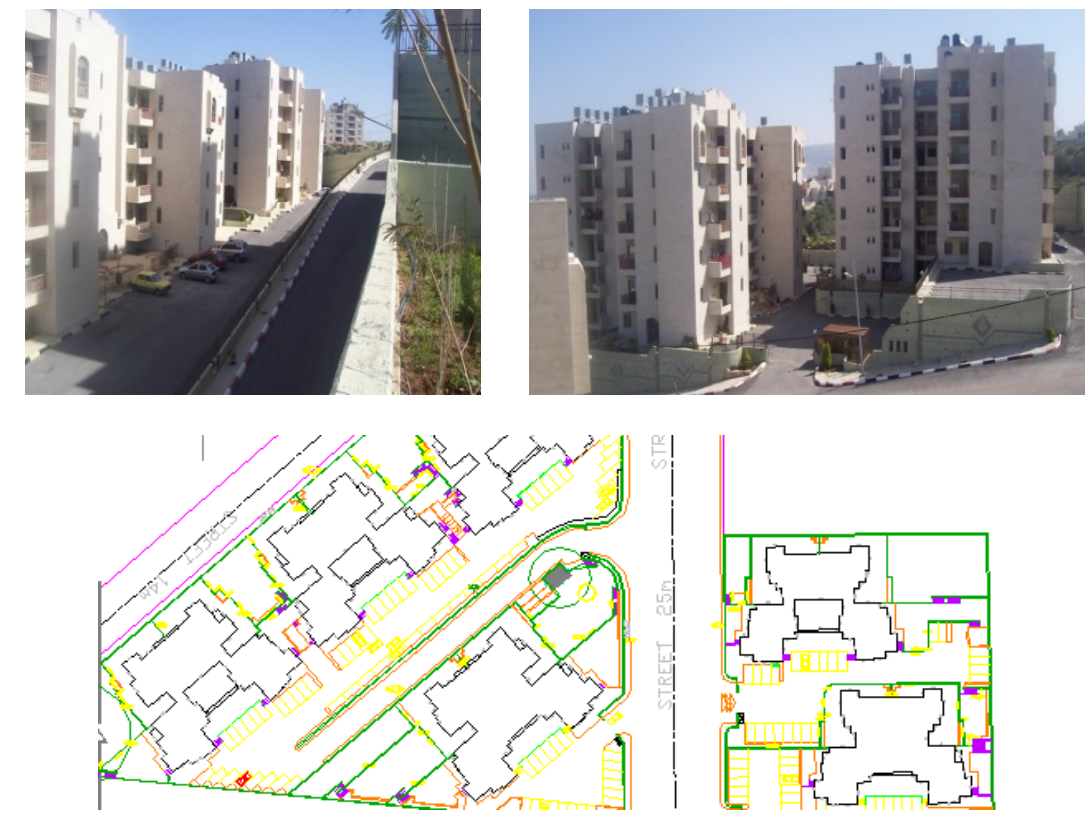

Figure 4: A high-rise high-density housing, Nablus city.

The third type of settlements is the traditional courtyard housing. It is located in the historical center of the city, and still highly populated. The following text will introduce characteristics and values of the traditional typologies in Palestine in general, and select samples in Nablus city.

\section{Traditional housing in Palestine}

Traditional housing in Palestine forms a low-rise compact fabric (2-3) floors. It can be noticed that the dominancy is for urban mass and not for space; the urban mass controls space and encloses it in the form of inner spaces (courtyards). Courtyards are a part of circulation system that served both functional and cultural needs.

On the unit level, the spatial organization of the house is mainly a cluster of spontaneous growth structures around a courtyard (fig. 5). Houses are in a harmony of heights (mostly 2-4 floors). Using of single houses or high-rise buildings is rarely found inside the traditional fabric. 

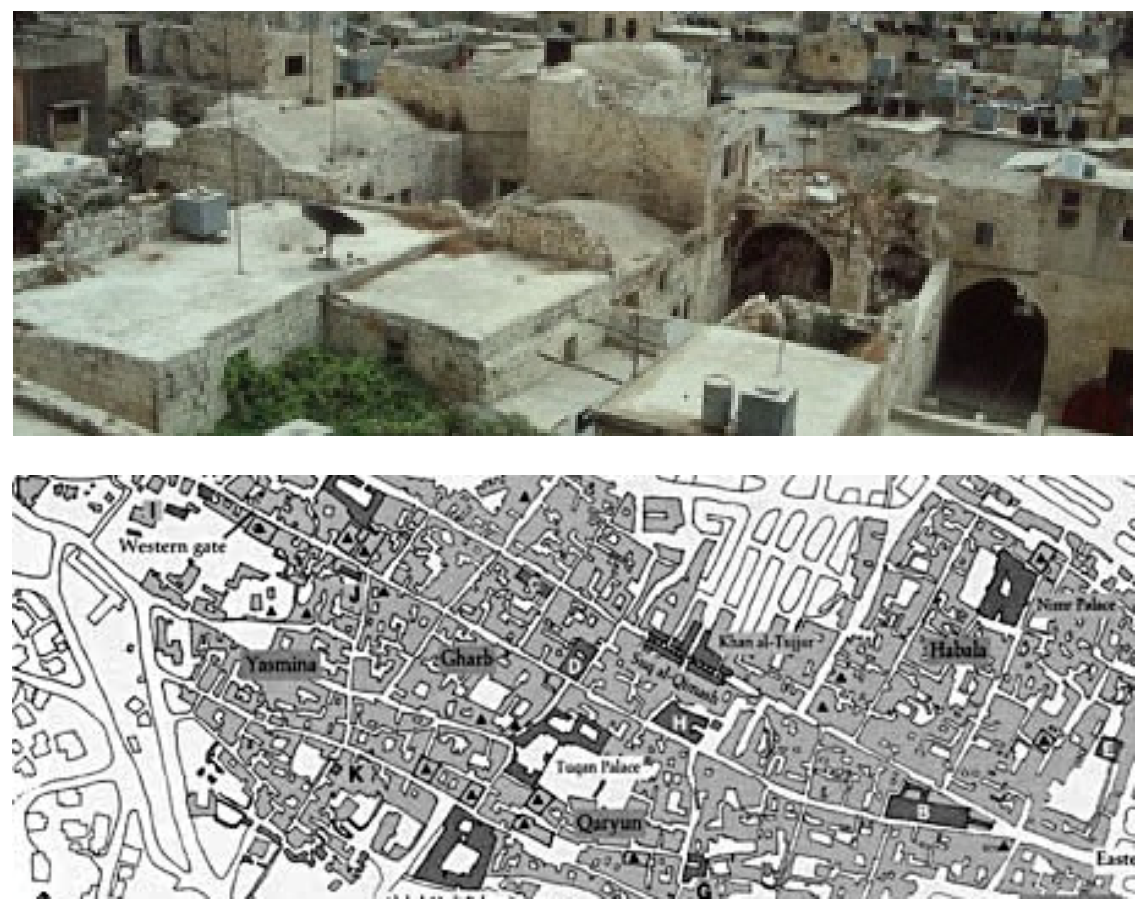

Figure 5: The compact fabric in Nablus old city (Doumani [9]).

\subsection{Values of traditional topologies}

Traditional typologies are forming a compact fabric which is an efficient strategy for preserving land. In the past, the courtyard allowed building wall to wall housing. One or more shared walls were used to be separations between houses. Required courtyards were not large, even in the large houses, because enlarging the courtyard leads for losing the shading benefits of it. Courtyards decrease the unused area and get the most benefit of the land (Sarkis et al. [5]). As courtyards are enough for the ordinary activities and social interaction, there are not a lot of public plazas in the traditional areas. This concept decreases the total area of the settlement. Comparing with the modern rule of viewing the whole perspective of the building, which needs the viewer to have a distance equals double the building height. If we apply this rule only on the public buildings in compact fabrics, the result would consume four to eight times of the original size (Nour [12]). Besides, human aspects and shading value would disappear. As a result, Low-rise compact fabric can contain a high-density of population, probably equivalent to high-rise dense fabric (Salamati [13]).

Compact fabric allows also for low cost infrastructure of residential areas. Streets can be thin and characterized by a high level of simplicity, because windows facing the street are not the main source for providing light and air. For the relatively small lands, the compact fabric is also a good strategy for decreasing the required services in the residential areas. It decreases the mobility of 
population which makes it possible to decrease car usage (Schittich [3]). So it gives the maximum efficiency with limited facilities.

Contrary to the current types of settlements, the traditional fabric is an organic fabric; this system is flexible and adaptable (Sarkis et al. [5]). The courtyard houses looks like living cells that have the ability to multiply and increase, without being odd in the majority. It is similar to a living organism (Ragette [4]). Housing design is naturally open ended, rather than most closed final forms, which are unable to accept changes (Rapoport [1]). In the past, Solutions for new needs took place in a simple way: If the family was expanded to have a new member, a new room was added to give the cluster of the composition more significance and richness. New rooms were simply integrated within the fabric. Traditional fabric also allows for multifunctional use of space. Private and public spaces have different uses at different times of day and night. The same space can be used in more than one way, as for circulation and social interaction.

The ability for adaptable re-use is also supported by the traditional typologies. Same concept of arranging spaces around a courtyard can be used, not only in designing residential buildings, but in public buildings too like: mosques, schools, and hospitals. (Nour [12]). Courtyard system can adapt to all these variations of functions with fewer modifications. This may extend the age of the building by accommodating new needs in minimum costs.

Courtyards make it possible to adapt the environment in simple ways. On the unit level, courtyards provide all families with qualified outdoor spaces, which offers natural light and sun (fig. 6). It may have fountains, and plantation that keeps the inner atmosphere cool and calm (Haj Hussein et al. [17]). Inner courtyards assist in modifying houses atmosphere during the various seasons. On the settlement level thermal comfort was also achieved by using the compact fabric. Seeking for comfort is not costly, shared walls are efficient insulation equipment for decreasing the exchange of heat between inside and outside houses (Sarkis et al. [5]). Collecting buildings together also stands against storms and wind carries sand.
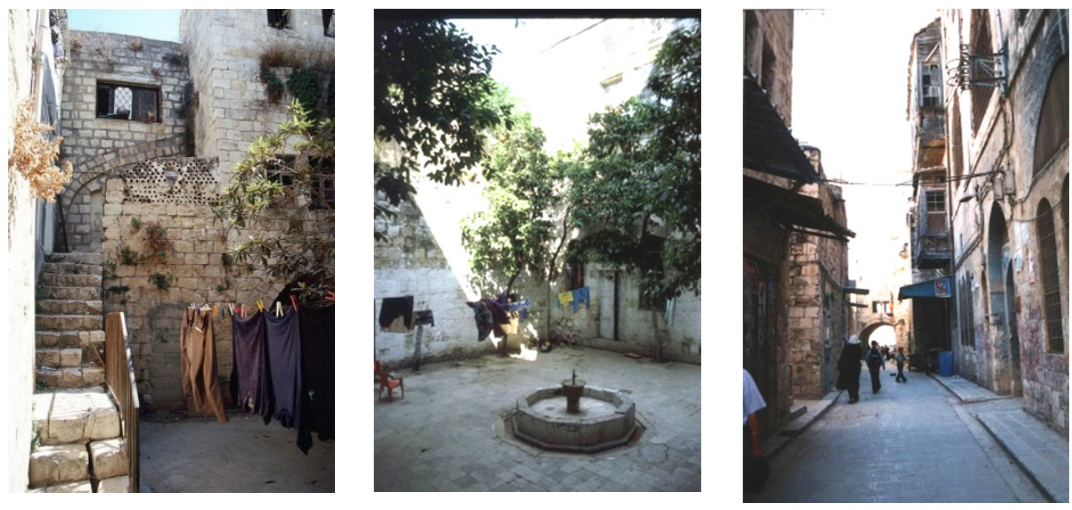

Figure 6: Private and public outdoor spaces in Nablus old city. 
On the social level, low-rise compact fabric offers private outdoor spaces in dense areas, which are very important issue in the Palestinians culture. It also allows for keeping the strength between the members of families, and encourages the social interaction (Hall [8]). Besides, residents can achieve their privacy inside the courtyard without being exposed to their neighbors. This is much better than private gardens in the contemporary typologies. Besides, Compactness allowed for imitating the mobility of people in the semi-private areas (Ragette [4]). It can control behavior by the narrow dimensions of streets, which discourage crowding and enable dynamic movement.

\section{Conclusion}

This paper aimed at learning from the traditional typologies to improve the current housing qualities in Palestine. Traditional typologies mainly delivered from the courtyard prototype. It was the main concept of housing design in Palestinian cities for centuries. It is also a possible choice for dealing with the contemporary problems, because it forms a compact fabric that is an efficient strategy for preserving land.

The traditional typologies has the advantages of both low-rise and high-rise independent typologies, as it can provide high-density with low rising, and private outdoor spaces in the dense areas. It also characterized the whole settlement with great values based on socio-cultural sustainability, which are rarely found in the contemporary housing: minimal waste of outdoor spaces, ability to growth, adaptability, environmental adequacy, and minimal infrastructure and services.

\section{Acknowledgement}

This paper is a part of a PhD study under the supervision of Prof. F. Ferreira \& Prof. M. M. Oliveira.

\section{References}

[1] Rapoport, A., House form and culture, Prentice- Hall, Engle wood cliffs: New Jersey, pp. 4-5, 47, 80, 1969.

[2] Pfeifer, G. \& Brauneck, P., Town houses: a housing Typology, Brikauser verlag: Basel, pp. 11-16, 2009.

[3] Schittich, C., In detail high-density housing, concepts, planning, construction, Bikhauser: Basel, Boston, and Berlin, pp. 10-19, 2004.

[4] Ragette, F., Traditional domestic architecture of the Arab region, American university of Sharjah: Sharjah, pp. 50-51, 2003.

[5] Sarkis, H., Allard, P. \& Hyde, T., (eds). Le Corbusier's Venice Hospital and the mat building revival, Prestel: New York, pp. 14-51, 71-75, 2001.

[6] Wolbier, J., Blueprint for Green affordable housing, Island Press: Washington, pp. 6, 2007. 
[7] Barker, R., Ecological Psychology: concepts and methods for studying human behavior, Stanford University presses: Stanford, pp. 3-10, 1968.

[8] Hall, E., The hidden Dimension, Anchor Books: New York, pp. 174, 1966.

[9] Doumani, B., Rediscovering Palestine: Merchants and Peasants in Jabal Nablus, 1700-1900, University of California Press: Berkeley, pp. 1-9, 1995.

[10] Caniggia, G. \& Maffei, G., Architectural composition and building typology, Alinea Editric: Firenze, pp. 70-72, 2001.

[11] Al-Amad, E., Continuity and change in traditional domestic architecture of Palestine: transformation of traditional concepts of house design in Nablus, PhD Thesis, University of Glasgow: Glasgow, pp. 1, 1998.

[12] Nour, A., An Analytical study of traditional Arab domestic Architecture, PhD Thesis, University of Newcastle Upon Tyne: Newcastle, pp. 15, 193, 1979.

[13] Salamati, A., Urban Housing in Iran. In Response to Socio-Cultural and Environmental Conditions, PhD Thesis, University of Strathclyde: Glasgow, pp. 2, 2001.

[14] Abu Obaid, M., Evaluation of Housing Projects in the West Bank-Case Study in Nablus , Ramallah, and Jenin Cities, Master theses, An-Najah N.U.: Nablus, pp. 86, 2013.

[15] Al-Amad, E., Traditional Concepts and New Housing Design in Palestine. Open House International Journal, 28(3), pp. 58-67, 2003.

[16] Abu hantash, I., and Salah, O., Housing and housing mortgage in Palestine, MAS: Ramallah, pp. 165, 2009.

[17] Haj Hussein, M., Barlet, A., \& Semidor, C., Socio environmental dimensions in outdoor spaces of contemporary Palestinian housing. Open House International Journal, 35(2), pp. 67-76, 2010.

[18] Zhu, Y., Neo-mat-building, The 4th International Conference of the International Forum on Urbanism (IFoU): Amsterdam/Delft, pp. 889-897, 2009.

[19] The World Bank, The Economic Effects of Restricted Access to Land in the West Bank, 2008.

[20] P. H. G., http://www.phg.org. 